\title{
Psychometric evaluation of the Questionnaire on Attitudes Towards Suicide (ATTS) in Poland
}

\author{
Patryk Stecz ${ }^{1}$ (D) \\ Published online: 26 February 2019 \\ (C) The Author(s) 2019
}

\begin{abstract}
The Questionnaire on Attitudes Towards Suicide (ATTS) is widely used to evaluate the views of an individual regarding acceptability of suicide and orientation towards suicide prevention. However, recent findings suggest that it requires some revision. The present study examines the factor structure of the ATTS questionnaire in two Polish samples, consisting of 239 students (sample one) and 128 students (sample two) of the helping professions. The previously-established 10-factor model was not supported by confirmatory factor analysis (CFA). Theoretical revaluation of the scale followed by factor analysis suggested that the best fit was provided by a five-factor model accounting for $48.2 \%$ of the variance. The adapted Polish ATTS questionnaire showed satisfactory reliability and validity; however, the factor loading patterns and factor structure varied from earlier studies. These improvements in the ATTS theoretical base and construct validity may enhance the utility of the revised scale.
\end{abstract}

Keywords Attitudes Towards Suicide $\cdot$ Suicide prevention $\cdot$ Gatekeepers $\cdot$ Validation $\cdot$ Psychometric scale

\section{Introduction}

Attitudes towards suicide are important for our understanding of suicidality, the experience of stigma or the helping behavior of the gatekeepers (Batterham et al. 2013; Gmitrowicz et al. 2015; Ringel 1983; Sisask et al. 2010; Stevens and Nies 2018; Wasserman 2016; World Health Organization 2010; Zalsman et al. 2016). Attitudes work as guidelines for decision making (Rokeach 1973), which has significant implications for the attitude-behavior relationship. If attitudinal objects are considered to be too threatening or psychologically demanding, it provokes prejudice and stigmatization (Jost et al. 2007; Moskowitz 2005). Although many instruments have been employed to measure attitudes towards suicide, no consensus

Electronic supplementary material The online version of this article (https://doi.org/10.1007/s12144-019-00185-1) contains supplementary material, which is available to authorized users.

Patryk Stecz

patryk.stecz@uni.lodz.pl

1 Department of Preventive and Addiction Psychology, Institute of Psychology, Faculty of Educational Sciences, University of Lodz, Lodz, Poland has been reached regarding the most feasible scale (Ghasemi et al. 2015; Kodaka et al. 2011).

Previous studies show that attitudes towards suicide are related to those towards suicide prevention (Hjelmeland et al. 2006; Sallander Renberg 2001). Sallander Renberg and Jacobsson (2003) distinguish them as two separate continua. Quite the contrary, Grimholt et al. (2014) suggest that positive attitude include empathy, compassion and acceptance of shortening someone's life full of suffering. Similarly, Gagnon and Hasking (2012) regard approving the client's right to decide when to die as an example of a positive attitude towards suicide among psychologists. Other researchers, however, conclude that attitudes hampering suicide prevention are negative (Bałandynowicz 2016). The terms positive and negative in suicide research encompass great diversity, and seem to overlap and conflict in particular areas. Overall, the literature supports the notion that attitudes towards suicide should be discussed together with attitudes towards suicide prevention.

Growing interest in understanding suicide prevention (Sallander Renberg 2001; Sallander Renberg and Jacobsson 2003) resulted in the introduction of new suicide screening questionnaires. This growth is believed to improve attitudes towards prevention by increasing the likelihood of asking about suicide and consequently breaking the taboo driven by fearful attitudes (Horowitz et al. 2012; Tait and Michail 2014). Fear triggers different potentially negative ways of helping 
behavior, including avoidance, denial or lower collaboration with patients who are more likely to die (Nia et al. 2016).

\section{Attitudes towards Suicide and Suicidality}

Several studies have shown that intolerant attitudes in the general population are found in regions typified by high numbers of suicides (Kerkhof and Natawat 1989; Reynders et al. 2016): This would suggest that attempts to obtain help may be impeded by the negative normative valuation of suicide by the local community, as well as by social and self-stigmatization (Ahmedani 2011; Reynders et al. 2014). In other words, helpseeking behavior may increase if a community shows more acceptance towards individuals at risk of suicide. Previous findings on the attitudes towards suicide and their outcomes in different populations are outlined in Table 1.

Evidence from universal and targeted intervention studies provide limited evidence for a causal relationship between attitudes towards suicide and suicidal behavior. Such interventions have mixed outcomes, including the observed effect of "more positive attitudes" on reducing suicide-related behavior (Robinson et al. 2013, p. 166), which should be interpreted with caution.

\section{Frequently Used and Recent Scales to Assess Suicide Attitudes}

The questionnaires on attitudes towards suicide vary with regard to their scale characteristics (theoretical base, number of dimensions, items and scoring system) and psychometric properties; however, only some have been tested for validity and reliability (Anderson et al. 2008; Herron et al. 2001; Kodaka et al. 2011; Sallander Renberg and Jacobsson 2003).

The Questionnaire on Attitudes Towards Suicide (ATTS), Suicide Opinion Questionnaire (SOQ) and Suicide Attitude Questionnaire (SUIATT) are all widely-recognized instruments for determining attitudes towards suicide (Diekstra and Kerkhof 1989; Ji et al. 2016; Kodaka et al. 2011; Sallander Renberg and Jacobsson 2003). They all offer an expert consensus on scale formulation, multidimensionality, a unified rating method and appropriateness for diverse study groups. Furthermore, they all address the theoretical basis of the attitude and have been evaluated for structure reproducibility. The SOQ and SUIATT questionnaires have certain shortcomings. For example, the SOQ scale originally comprised 100 items, its validity lacks a solid theoretical foundation, and its scale structure struggles from a lack of reproducibility. Domino reported inconsistent findings regarding the dimensionality of the SOQ, which varied from 5 to 15 factors (Domino 1980; Domino et al. 1982) SUIATT seems too complex with 19 manually constructed subscales. Better reliability is offered by the 34-item ATTS (Anderson et al. 2008). In addition, the SUIATT has been criticized for its complexity, comprising 63 items, which could be a threat to feasibility in clinical settings (Kodaka et al. 2011).

More recently, several researchers have evaluated positive and negative attitudes towards suicide among physicians using an 11-item Understanding of Suicidal Patients Scale

Table 1 Correlates and outcomes of different attitudes towards suicide in chronological order

\begin{tabular}{|c|c|c|c|}
\hline Author & Aspect of attitude towards suicide & Population & Outcomes and correlates \\
\hline Farberow (1989) & Permissive attitude & General & Risk factor in society (higher suicide rates) \\
\hline Kerkhof and Natawat (1989) & Intolerant attitude & General & $\begin{array}{l}\text { Risk factor for community (higher suicide rates), } \\
\text { protective factor for individual }\end{array}$ \\
\hline Herron et al. (2001) & Negative attitudes towards suicide & $\begin{array}{l}\text { Psychiatrists, general } \\
\text { practitioners, nurses }\end{array}$ & Ineffective management of suicide risk \\
\hline McAuliffe et al. (2003) & Suicide as a right & General & Risk factor for suicidal ideations \\
\hline Zadravec et al. (2006) & Suicide acceptance & General & Decreased life satisfaction \\
\hline Brunero et al. (2008) & $\begin{array}{l}\text { Attitudes holding clinicians } \\
\text { against prevention }\end{array}$ & Gatekeepers & Inaccurate risk assessment and management skills \\
\hline $\begin{array}{l}\text { Gearing and Lizardi (2009), } \\
\text { Sisask et al. (2010) }\end{array}$ & Restrictive attitude & General & Protective factor $^{\mathrm{a}}$ \\
\hline Arnautovska and Grad (2010) & Permissive attitude & Adolescents & Risk factor for suicidal behavior $^{2}$ \\
\hline Wasserman (2016) & Suicide related attitudes in general & $\begin{array}{l}\text { Health services, medical } \\
\text { staff }\end{array}$ & Predictor of quality of healthcare and suicide prevention \\
\hline Schmidt (2016) & Ambiguity and uncertainty & Gatekeepers & Low self-preparedness to assess the risk and prevent \\
\hline Zalsman et al. (2016) & Attitudes towards suicide & $\begin{array}{l}\text { Decision-makers and } \\
\text { prevention officers }\end{array}$ & $\begin{array}{l}\text { Predictor of developing and implementing prevention } \\
\text { strategies }\end{array}$ \\
\hline Winterrowd et al. (2017) & $\begin{array}{l}\text { Favourable attitudes about } \\
\text { older adult suicide }\end{array}$ & $\begin{array}{l}\text { Older adults and young } \\
\text { adults }\end{array}$ & $\begin{array}{l}\text { Older adult suicide script triggered by favourable } \\
\text { attitudes, health problems, low religiosity and no } \\
\text { supportive relationships }\end{array}$ \\
\hline
\end{tabular}

${ }^{\text {a }}$ A restrictive attitude against suicide may act as a protective factor due to mediating effect of religiousness (Sisask et al. 2010) 
(USP) (Grimholt et al. 2014; Suominen et al. 2007). Positive attitude was defined in terms of commitment, empathy and willingness to provide care for suicide attempters; however, agreement with euthanasia and accepting suicide as shortening an incurable illness are regarded as positive understanding of suicidal patient, and this is not explained in the study. Although the results indicate that the emotions of the physicians play an important role towards individuals at risk of suicide, insufficient information is available on the theoretical basis of the USP.

To date, only a few studies have examined stigmatizing attitudes toward people who commit suicide (Batterham et al. 2013; Williams et al. 2018). The Stigma of Suicide Scale (SOSS) and its 16-item short form (SOSS-SF) have been developed to examine attitudes towards "a prototypical person who completed suicide" (Batterham et al. 2013). Although it is difficult to precisely define such a prototype, the questionnaire is nevertheless argued to provide valid results. The SOSS-SF reported high internal validity with a three-factor structure (stigma, isolation/depression and glorification/normalization) (Batterham et al. 2013; Williams et al. 2018). Stigma reflects a strong negative perception of the individual, while attitudes refer to more complex evaluation of an object expressed by cognitions, emotions and behavior. It is to be hoped that further exploration of stigmatization will increase the understanding of suicidality among the community and facilitate help seeking. Regarding the SOSS, more research is required to confirm its factor stability; the items loading the glorification factor tend to outrange the concept of stigma, which deserves more scientific discussion.

\section{Sallander Renberg and Jacobsson Model of Attitudes towards Suicide}

Only a few attempts have been made to incorporate the cognitive-emotional-behavioral model in the development of suicide attitude scales (Diekstra and Kerkhof 1989; Ghasemi et al. 2015; Kodaka et al. 2011; Sallander Renberg and Jacobsson 2003). The theoretical framework for attitudes towards suicide in the present article is based on that given by Sallander Renberg (2001) and Sallander Renberg and Jacobsson (2003). They define attitudes towards suicide as multidimensional valuations of the most critical aspects of suicidal behavior or death wishes, these being manifested in emotional, instrumental (conative, volitional) and cognitive components (Allport 1935). These attitudes can be expressed differently according to referent level (self, significant others, people in general) (Diekstra and Kerkhof 1989), category and severity of circumstances (incurable disease, loneliness).

Sallander Renberg and Jacobsson (2003) argue that some critical aspects exist regarding attitudes towards suicide: comprehensibility (acceptance or disapproval), consent (suicide as a human right) and preventive orientation (caring for those at suicide risk and readiness to prevent).

Difficulty arises when an attempt is made to fit dimensions such as suicide as a process or suicide as a relation-caused event into the general concept of attitude (Hitlin and Pinkston 2013; Rokeach 1973). It seems questionable whether Sallander Renberg and Jacobsson make a clear distinction between the term attitude and particular cognitions related to suicide. An individual's opinions on whether suicide is a process refer to causal attributions and have no relevance to attitude measure. The rationale for incorporating these attitudinal dimensions in the model was mainly based on their face validity, as confirmed by experts in the field, and the previous use of similar concepts in the SOQ scale (Domino et al. 1982).

\section{Development of a Questionnaire on Attitudes Towards Suicide (ATTS)}

Most of the baseline set of the items included in the ATTS was derived from the SOQ (Domino et al. 1982) followed by a pool of new questions introduced to include referent levels, a theoretical extension introduced by Diekstra and Kerkhof (1989). They argue that a concept of the attitude towards suicide should (a) incorporate affective, instrumental and cognitive components, (b) should apply to the individual respondent or significant other rather than to people in general, i.e. comprising different referent levels and (c) should address different types of objects (a person with suicidal behavior and the suicide act itself).

Ultimately, 40 ATTS items underwent EFA with varimax rotation, which resulted in a 10-factor model being obtained for 34 items with satisfactory loadings $(>0.40)$ and communalities $(>0.40)$. Those factors were named Suicide as a right (7-item Factor 1, $\alpha=0.86$, e.g. "Give help to commit suicide if severe, incurable disease-people"), Incomprehensibility (5item Factor 2, $\alpha=0.72$, e.g. "Not understandable that people can take their lives"), Noncommunication (5-item Factor 3, $\alpha=0.64$, e.g. "People who make threats seldom complete suicides"), Preventability (3-item Factor 4, $\alpha=0.63$, e.g. "Suicide can be prevented"), Tabooing (3-item Factor 5, $\alpha=0.45$, e.g. "Should or would rather not talk about suicide"), Normal-common (3-item Factor 6, $\alpha=0.51$, e.g. "Everyone has considered suicide"), Suicide as a process (2-item Factor 7, $\alpha=0.51$, e.g. "Suicides considered for a long time"), Relation-caused (2-item Factor 8, $\alpha=0.45$, e.g. "Attempts due to interpersonal conflicts"), Preparedness to prevent (2-item Factor 9, $\alpha=0.38$, e.g. "Prepared to help a suicidal person - myself") and Suicide as solution or resignation (2-item Factor 10, $\alpha=0.54$, e.g. "Situations where suicide is the only solution") (Sallander Renberg and Jacobsson 2003). 


\section{ATTS in Need of Revision}

The problem with the ATTS scale is related to consistency of attitude categories identified by Sallander Renberg and Jacobsson (2003) with theoretical ground. The tool is aimed at incorporating the tripartile model of attitude and diverse referent levels. In particular, factors 1 (suicide as a right), 2 (incomprehensibility) and 10 (resignation - suicide as a solution) were found to relate to the acceptance of suicide and its normative valuation, which is consistent with the theoretical basis. They additionally include various reference levels (self, people in general). Factors 4 (preventability) and 9 (preparedness to prevent) focus on attitude towards prevention, which addresses a separate and relevant attitude object. To conclude, five factors $(1,2,4,9,10)$ of the original tendimensional ATTS seem to be grounded in the theory of attitudes.

The ATTS items were developed based on expert opinions and in accordance with the SOQ, which might have resulted in certain drawbacks in terms of factor interpretability. It is difficult to recognize any attitude component in factor 3 (noncommunication of suicidal behavior), factor 7 (suicide as a process) or factor 8 (suicide as relation-caused): They appear to focus on certain beliefs and factual knowledge related to suicide instead of the feelings and behavioral tendency of the individual towards the attitude object. Although the approach to suicide perception given by Sallander Renberg and Jacobsson (2003) is comprehensive, it does not appear to fit the attitude structure and functions very well in the current ATTS design.

The design of the ATTS is also an issue of concern, one weakness being that factors 7-10 (suicide as a process, suicide as relation-caused, preparedness to prevent, suicide as a solution) are defined by only two variables. In general, twoitem subscales are believed to offer inadequate content validity. Factors 7 to 10 therefore appear to be weak and unstable, which is confirmed by low internal consistency values (Sallander Renberg and Jacobsson 2003).

The internal consistency levels of the ATTS were generally acceptable for most factors, except for factors 5, 8, and 9 (Cronbach's $\alpha$ values of $0.38-0.45$ ). Factors $6-10$ explained a relatively low proportion of variance $(17.2 \%$ in total).

Another problem with the factor analysis performed in the second wave is that insufficient information is given regarding the extraction method, and the choice of an orthogonal rotation solution is not justified. For example, a negative correlation between factor 1 (suicide acceptance) and factor 2 (incomprehensibility) should be expected.

In addition, the stability of the ATTS factors remains unclear, with factor analyses conducted in three different studies (data from Ghana, Uganda, Norway, Korea, United States) indicating dissimilarities in ATTS factor structure (Hjelmeland et al. 2008; Ji et al. 2016; Williams and Witte
2018). The choice of factor analysis can also play a role. A Korean study aimed at identifying a culturally-unique factor structure identified an 11-factor solution which was found to be valid with the use of EFA but not CFA (Ji et al. 2016).

In a larger study in Ghana, Uganda and Norway, three separate factor analyses were conducted to compare the structural equivalence of the instrument between different cultures (Hjelmeland et al. 2008). Each sample demonstrated different factor numbers and face structure, varying from 12 to 14 factors. Hjelmeland et al. (2008) found that in its original form, the ATTS also examines attitudes towards suicide prevention, factual knowledge and myths related to suicides, apart from the wide range of attitudes given by Sallander Renberg and Jacobsson (2003).

In an internet-based study on undergraduates, Williams and Witte (2018) used EFA to examine the ATTS based on low internal consistency coefficients of the Sallander Renberg and Jacobsson (2003) ten scales. The authors proposed an interpretable model with remaining 14 items. The three-factor model had adequate fit and improved internal consistency: right to die $(\alpha=.77)$, inevitability $(\alpha=.68)$ and comprehensibility $(\alpha=.62)$. Williams and Witte (2018) were likely to identify the most robust ATTS factors and items.

ATTS factor stability, inappropriate questionnaire design and cultural differences may be potential sources of inconsistent findings. As suicidal behavior is perceived differently according to normative standards by the community, individual attitudes towards suicide are determined more by their social meaning at a cultural level (Hjelmeland et al. 2008). Cultural differences may thus affect ATTS factor structure and loadings between countries.

\section{Aim of the Study}

The aim of the study was to develop a revised version of the ATTS and examine its psychometric properties in the Polish community of students in the helping professions. The revised ATTS was expected to face some major limitations outlined in previous studies (Hjelmeland et al. 2008; Ji et al. 2016; Sallander Renberg and Jacobsson 2003; Williams and Witte 2018). First, the original 10-factor model (Sallander Renberg and Jacobsson 2003) was evaluated for its reproducibility. The questionnaire structure and design were critically reviewed and modified in order to provide an improved fit of the item set to the theoretical ground proposed by Sallander Renberg and Jacobsson (2003). In order to evaluate a theorized model in the Polish cultural background, EFA was used. Ultimately, CFA was conducted to cross-validate the proposed five-factor model. EFA and CFA were therefore conducted in two separate samples.

Another goal was to determine the reliability of the Polish revised ATTS and provide preliminary data on its validity. Although no directly analogous tool exists in Polish language, 
the ATTS was compared to other well-established questionnaires measuring the related concepts. Possible correlations would give support for criterion validity of the ATTS. The study is intended to address the original failings of the ATTS and the need for a suicide attitudes scale for further research on gatekeepers in Poland.

Specifically, CFA was used to test the hypothesis that the responses to the revised ATTS would correspond to the five components of attitudes towards suicide and suicide prevention.

Hypothesis 1. As the revised version of the ATTS is considered a five-dimensional construct: a 5-component model of ATTS (suicide as a right, preventability-cognitive, suicide as a solution with reference to self, incomprehensibility-comprehensibility and orientation towards prevention-instrumental) would be expected to fit the data.

Since suicidal behavior and individualistic personal values are known to be positively correlated with suicide acceptance (Arnautovska and Grad 2010; Eskin 2013; McAuliffe et al. 2003), a second hypothesis (H2) was that the relationship between those constructs and attitudes towards suicide could be used to estimate the ATTS criterion validity.

Hypothesis 2. Attitudes towards suicide would be related to (a) individualistic personal values and (b) suicidal behavior:

H2 (a): Positive attitudes towards suicide (represented by suicide as a right, suicide as solution with reference to self and incomprehensibility-comprehensibility) would be associated with higher importance given to freedom and independence values in the personal values hierarchy,

H2 (b): Positive attitudes towards suicide (represented by suicide as a right, suicide as solution with reference to self and incomprehensibility-comprehensibility) would be positively associated with suicidal behavior.

\section{Methods}

\section{Study Design}

To establish the validity and reliability of the ATTS, the study was conducted in three stages.

Initially, the original ATTS items in English were translated into Polish for use in the study (Appendix 2 and 3).

In the next phase, an initial sample of 239 participants (Sample 1) was used to (a) evaluate the ten-factor model proposed by Sallander Renberg and Jacobsson (2003), (b) choose non-essential and irrelevant questionnaire items to be eliminated, (c) determine a possible factor structure for the revised ATTS with the use of EFA. In order to cross-validate the proposed factor structure with the use of CFA, a second sample of 128 participants (Sample 2) was recruited. Following this, data from samples 1 and 2 were used to assess the criterion validity, concurrent validity, discriminant validity and reliability of the ATTS.

\section{Subjects}

The group of study participants comprised potential gatekeepers such as students of Medicine, Psychology, Education Science and Law. In this sense, a gatekeeper is understood as a healthcare provider or a professional from outside the health sector (e.g. education, justice, counselors) who may interact with people experiencing individual or family crisis (Goldsmith et al. 2002; van der Feltz-Cornelis et al. 2011). A total of 367 participants was included in the study, comprising two successive samples of 239 and 128 subjects.

The first sample was selected from the pool of 246 undergraduates studying Psychology, Law or Medicine in Higher Education Institutions in Lodz, Poland. The subjects were selected from participants on an obligatory course. In total, 242 of the students agreed to complete the questionnaires and demographic items (response rate of $98.4 \%$ ). Due to missing data, three participants were excluded, resulting in sample one comprising 239 individuals. The mean age of participants was $22.84(\mathrm{SD}=5.15)$.

The second sample was selected for the purpose of crossvalidation of the revised ATTS (Appendix 3) from 129 undergraduates studying Education Science: an obligatory course (mean age 22.86, SD=2.99). From these, 129 questionnaires were returned. Due to missing data, one subject was excluded. More detailed information on study participants is given in Table 2 .

\section{Instruments and Procedure}

The study was approved by the institutional ethical board. The tools used in the study comprised the ATTS scale, together with additional instruments used to assess the criterion validity of the instrument. Subscale "D" from the General Health Questionnaire (GHQ-28) was chosen to evaluate the relationship between suicidal behavior and permissive attitude towards suicide. Additionally, selected items from the Rokeach Value Survey (RVS) were analyzed to assess the relationship between the attitudes and critical personal values. As values are acknowledged to be more stable and have a more central meaning than attitudes (Grube et al. 1994), it was hypothesized that a mild to moderate relationship existed between suicide-related attitudes and critical values. 
Table 2 Study participant characteristics

\begin{tabular}{|c|c|c|c|c|c|}
\hline & & \multicolumn{2}{|c|}{ Sample one } & \multicolumn{2}{|c|}{ Sample two } \\
\hline & & $\mathrm{N}$ & $\%$ of $\mathrm{N}$ & $\mathrm{N}$ & $\%$ of $\mathrm{N}$ \\
\hline \multirow[t]{2}{*}{ Sex } & Female & 166 & 69.5 & 90 & 70.3 \\
\hline & Male & 73 & 30.5 & 38 & 29.7 \\
\hline \multirow[t]{4}{*}{ Relationship status } & Single & 109 & 45.6 & 57 & 44.5 \\
\hline & Couple or married & 121 & 50.6 & 69 & 53.9 \\
\hline & Separated or divorced & 7 & 2.9 & 1 & 0.8 \\
\hline & Unknown & 2 & 0.9 & 0 & 0.0 \\
\hline \multirow[t]{2}{*}{ Children } & No & 219 & 91.6 & 122 & 95.3 \\
\hline & Yes & 20 & 8.4 & 6 & 4.7 \\
\hline \multirow[t]{3}{*}{ Income } & Low & 3 & 1.3 & 5 & 3.9 \\
\hline & Medium & 127 & 53.1 & 69 & 53.9 \\
\hline & High & 109 & 45.6 & 54 & 42.2 \\
\hline \multirow[t]{3}{*}{ Residential area } & Rural & 43 & 18.0 & 30 & 23.4 \\
\hline & Semi-urban & 27 & 11.3 & 34 & 26.6 \\
\hline & $\begin{array}{l}\text { (Cities below } 25,000 \text { citizens) } \\
\text { Urban }\end{array}$ & 169 & 70.7 & 64 & 50.0 \\
\hline
\end{tabular}

\section{GHQ-28}

The General Health Questionnaire (GHQ) was developed to assess the likelihood of psychological disorders. The Polish version (Goldberg et al. 2001) shows good psychometric properties and is characterized by good reliability regarding each factor (somatic symptoms, anxiety and insomnia, social dysfunction and suicidal/severe depression symptoms). Subscale D comprises suicidal depression symptoms and indices of suicidal behavior (i.e. "Have you recently found yourself wishing you were dead and away from it all?"). The Polish version reproduces the original factor structure. A scoring method based on a Likert scale of 0 to 3 was chosen in order to increase the sensitivity of the measurement.

\section{RVS}

The Rokeach Value Survey (Rokeach 1973) was developed to rank the guiding principles in the individual's life. The author suggests that specific beliefs and attitudes are associated to the fundamental values which are central and more stable. Csikai (1999) found that personal values play a significant role in predicting attitudes towards euthanasia and assisted suicide among gatekeepers. The questionnaire consists of 18 instrumental values and 18 end-state (terminal) values, which are ranked by the respondent in a hierarchy from 1 (most preferable) to 18 (least desirable).

\section{Statistical Analyses}

The analyses were performed using IBM SPSS Statistics 25.0, AMOS 25.0 for Windows and Microsoft Excel. CFA was first performed on Sample 1 to evaluate the original 34-item ATTS factorability. Next, the slope of eigenvalues and careful item analysis were used for making decisions about the number of factors tested by EFA. As it was expected that a multi-factor structure with several factors correlated to each other would be yielded, an oblique rotation solution was performed. Based on (a) the analysis of the ATTS theoretical base, (b) univariate correlation analysis and (c) EFA results, a five-factor structure was hypothesized, which was then confirmed by CFA on sample two.

Because Cronbach's alpha may be biased in relatively short scales and this study incorporates factor analysis, composite reliability coefficient (CR) was obtained for estimating internal consistency (Peterson and Kim 2013). A significance level below 0.05 was considered statistically significant.

\section{Results}

\section{Stage 1: Polish Back-Translation of the ATTS Scale}

The 34-item ATTS (Sallander Renberg and Jacobsson 2003) was translated into Polish. Each question was given on a 5point Likert scale.. The adaptation was proceeded by a translation and a back-translation. Permission was obtained from the original authors for the adaptation. Two independent forward translations of the ATTS scale were made by one expert in Polish and English (a sworn translator) and by one expert in Psychology, Polish and English. The translations into Polish were merged into one by a single expert in Psychology, Polish and English. Consequently, another expert in Polish and English (a certified translator) translated the merged Polish 
version into English. On this basis, two Polish-English experts verified the coherence of both the original scale (obtained from Renberg Sallander) and the back-translated English version. The final back-translated version was sent for the approval of the original authors. Using back-translation procedure and its results indicate that the Polish version could be administered for the purpose of this study.

CFA was also performed assuming a 10-factor structure by analyzing the unchanged 34 items. The Polish backtranslation was supplemented by four additional statements from the 40 -item ATTS version used previously by Sallander Renberg and Jacobsson (2003). Those items, further described in the item elimination section, were used in the next stage of the study to improve the content validity of the ATTS and its item relevance.

\section{Stage 2: Development of a New Model Structure}

\section{Confirmatory Factor Analysis of the Original Ten-Factor Model}

The data in was screened for univariate outliers. No out-ofrange values were identified. The minimum amount of data for factor analysis was satisfied, with a final size of sample one being 239 , thus giving a ratio of over six cases per variable. The requirement for a minimum sample size of 200 cases specified by Arrindell and van der Ende (1985) was met, as was the five subjects-to-variable ratio rule, specified by MacCallum et al. (1999). This rule of thumb was also met according to sample two.

CFA was carried out in sample one to validate the tenfactor-model comprising 34 items proposed by the ATTS authors. As shown in Table 4, the fit indices suggest that the 10factor solution was not an adequate representation of the data. This indication was supported by the examination of internal consistency values: The Cronbach's alpha coefficients for the previously established 10 factors in the ATTS varied from 0.14 to 0.84 , with only five factors in the Polish sample reaching a level of 0.5 . In order to improve data fit, modification indices were used to covary error terms that are part of the same factor. Model fit parameters did not change considerably (RMSEA $=0.057$; $\mathrm{CFI}=0.81$; $\mathrm{GFI}=0.83, \mathrm{CMIN} / \mathrm{DF}=1.768$ ).

The results of CFA indicated that a new model structure of the ATTS should be considered and examined.

\section{Item Inclusion and Elimination}

\section{Criterion One: Absence of Theoretical Coherence}

To increase the number of items potentially congruent with the underlying constructs, previous versions of ATTS, used by Sallander Renberg and Jacobsson (2003), were carefully evaluated. This required the back-translation of four additional statements: item \#8 (people who commit suicide are usually mentally ill), item \#14 (loneliness could for me be a reason to take my life), item \#21 (suicidal thoughts will never disappear) and item \#25 (a suicide attempt is a cry for help).

Following this, items \#7 (attempts due to revenge and punishment), \#10 (suicides considered for a long time), \#12 (people who make threats seldom complete suicide), \#17 (could express suicide wish without meaning it - myself), \#22 (suicide happens without warning), \#23 (most people avoid talking about suicide), \#27 (relatives have no idea about what is going on), \#32 (people who make threats seldom complete suicide) and \#34 (attempts due to interpersonal conflicts) were not found to be congruent with any attitudinal construct; \#23 did not refer to personal views. These items were eliminated.

\section{Criterion Two: Low Item Intercorrelations}

In order to examine the factorability of the remaining 29 ATTS items, the variables that correlated with a group of other variables were identified. Items with less than two bivariate correlations of 0.3 or higher were, therefore, excluded. This choice was based on the assumption that two-item factors would be considered a potential threat to the quality of factor solutions.

A considerable number of items did not meet the specified criteria: the excluded items were: \#8 (suiciders are mentally ill), \#11 (risk to evoke suicidal thoughts if asked about \#13 (should or would rather not talk about suicide), \#21 (suicidal thoughts will never disappear) and \#26 (not understandable that people can take their lives). The items excluded on the previous stage did not display correlations either.

\section{Criterion 3: Skewness and Kurtosis}

Next, each of the remaining 24 items was scrutinized for the acceptable range of skewness and kurtosis which was below 1.5 and above -1.5 (Tabachnick and Fidell 2013). Skewed data was managed by subjecting six variables for log transformation (\#6 - suicide decision cannot be reversed, \#24 - suicide one's own business, \#25 - attempts a cry for help, \#29prepared to help a suicidal person - myself, \#36 - suicide can be prevented, \#37 - suicide should not always be prevented). No item was eliminated at this stage.

\section{Criterion 4: Communalities}

For the EFA, the maximum likelihood method was chosen, as it allows the goodness of the model fit indexes to be computed (Fabrigar et al. 1999). The oblimin rotation method was chosen on the assumption that several factors might be associated with each other (i.e. the emotional and cognitive component). The initial EFA solution with 24 items had too many low 
communalities to provide an interpretable model; therefore five items (\#4 - attempts are impulsive actions, \#5 - suicide understandable if severe, incurable disease - people, \#15 everyone has considered suicide, \#25 - attempts a cry for help, \#30 - anybody can commit suicide) with very poor communalities (ranging from 0.21 to 0.36 ) were removed.

The analysis was repeated with the remaining 19 items. Although the EFA solution indicated a interpretable fivefactor model, item number 18 (suicide a relief), comprising factor 1 (suicide as a right), had low discriminative power and was extraneous. Since there was no threat to the content validity of factor 1 , represented by six items, item number 18 was eliminated.

\section{New Model Description}

A final five-factor solution (maximum likelihood) explaining $48.2 \%$ of total variance and with a fair goodness-of-fit $\left[\chi^{2}(73)=96.754, p=0.033\right]$ was proposed (Table 3 ) for the remaining 18 items. The five principal components would account for $62.4 \%$ of the total variance. The remaining 18 items (Appendix 1) were related to suicide acceptance, suicide incomprehensibility and the orientation towards suicide prevention. A Kaiser-Meyer-Olkin value of 0.85 suggests that the sampling was adequate as it fits the recommended range between 0.8 and 1 (Cerny and Kaiser 1977). An analysis of the anti-image matrix found the Measures of Sampling Adequacy (MSAs) to range from 0.71 (item 29 - prepared to help a suicidal person - myself) to 0.93 (item 37 - suicide should not always be prevented). Bartlett's test of sphericity showed that the variables were related to each other and that they were suitable for structure detection $\left[\chi^{2}(153)=1383.523, p<\right.$ $0.001]$. Each factor was loaded by a minimum of three items, and the factor loadings were satisfactory. In addition, all factors reported satisfactory reliability based on internal consistency (Cronbach's alpha) and composite reliability (CR) coefficient.

The minimum acceptable loading value for an item was set at 0.32 according to the rule of thumb proposed by Tabachnick and Fidell (2013). The strongest factor was " 1 - suicide as a right" with six items, and its factor loadings varied from 0.52 to 0.83 . The weakest factor was " 4 - incomprehensibility / comprehensibility", with three items and factor loadings varying from 0.43 to 0.60 .

Although the communalities for items 1 - can always help (0.35) and 29 - prepared to help a suicidal person - myself $(0.32)$ were poor, they comprised theoretically consistent factors (attitude towards prevention - cognitive and instrumental).

Items 19 (suicides among younger people particularly puzzling) and 29 (prepared to help a suicidal person-myself) had relatively low factor loadings and they cross-loaded onto other factors. Removing items 19 and 29 would result in obtaining two-item factors, which was unacceptable.

\section{Confirmation of the Five-Factor Model}

The resulting factor solution identified by the EFA was tested with CFA in order to determine whether the model fits the data. Participants from sample two were administered an 18item version of the ATTS (Appendix 3). Factors 1 - suicide as a right, 3 - suicide as solution with reference to self and 4 incomprehensibility - comprehensibility were related to suicide permissiveness, while factors 2 - preventability - cognitive component and 5 - preventability - instrumental component would describe the cognitive and instrumental aspects of attitudes towards suicide prevention.

The proposed five-factor model was found to be more acceptable than the original 10-factor solution; however, the CFI (comparative fit index) and GFI (goodness of fit index) values only approached the 0.9 level (Table 4). The RMSEA (root mean square error of approximation) and RMR (root mean square residual) values suggested an acceptable goodness of fit. In order to improve the model fit, high modification indices were scrutinized. The unique factors belonging to the same subscale (e4-e5, e3-e6 and e4-e1 belonging to factor 1) were covaried. Composite reliability coefficients (McDonald's Omega) indicate that the cross-validated model has similar estimated reliability to the model proposed and yielded by EFA (Table 3).

In order to assess the discriminant validity of the scale, the mean factor scores for each dimension among males and females were computed and scrutinized for correlations. The cross-validated model found no mean differences in factor mean scores between females and males. Positive correlations between the five factors (ranging from 0.17 to 0.82 ) suggest that the scale possesses satisfactory discriminant validity (Table 5): CFA confirmed that the model consists of five interrelated but not redundant constructs.

\section{Stage 3: Criterion Validity}

Suicidal depression subscale of the GHQ-28 (including suicidal ideations, life-weariness and death wishes) was positively associated with two ATTS factors: suicide as a right and suicide comprehensibility (Table 6). Interestingly, study participants who displayed more severe suicidal behavior tended to hold stronger beliefs that suicide can be prevented $(\mathrm{r}=0.56$, $p<0.001)$.

Another method of assessing the criterion validity was by comparing the individual level of suicide acceptance with the importance of certain related personal values. It was expected that suicide as a right would have a moderate to strong association with the positions of the freedom value and the independence value in the personal values hierarchy. The correlations were weak or insignificant. 


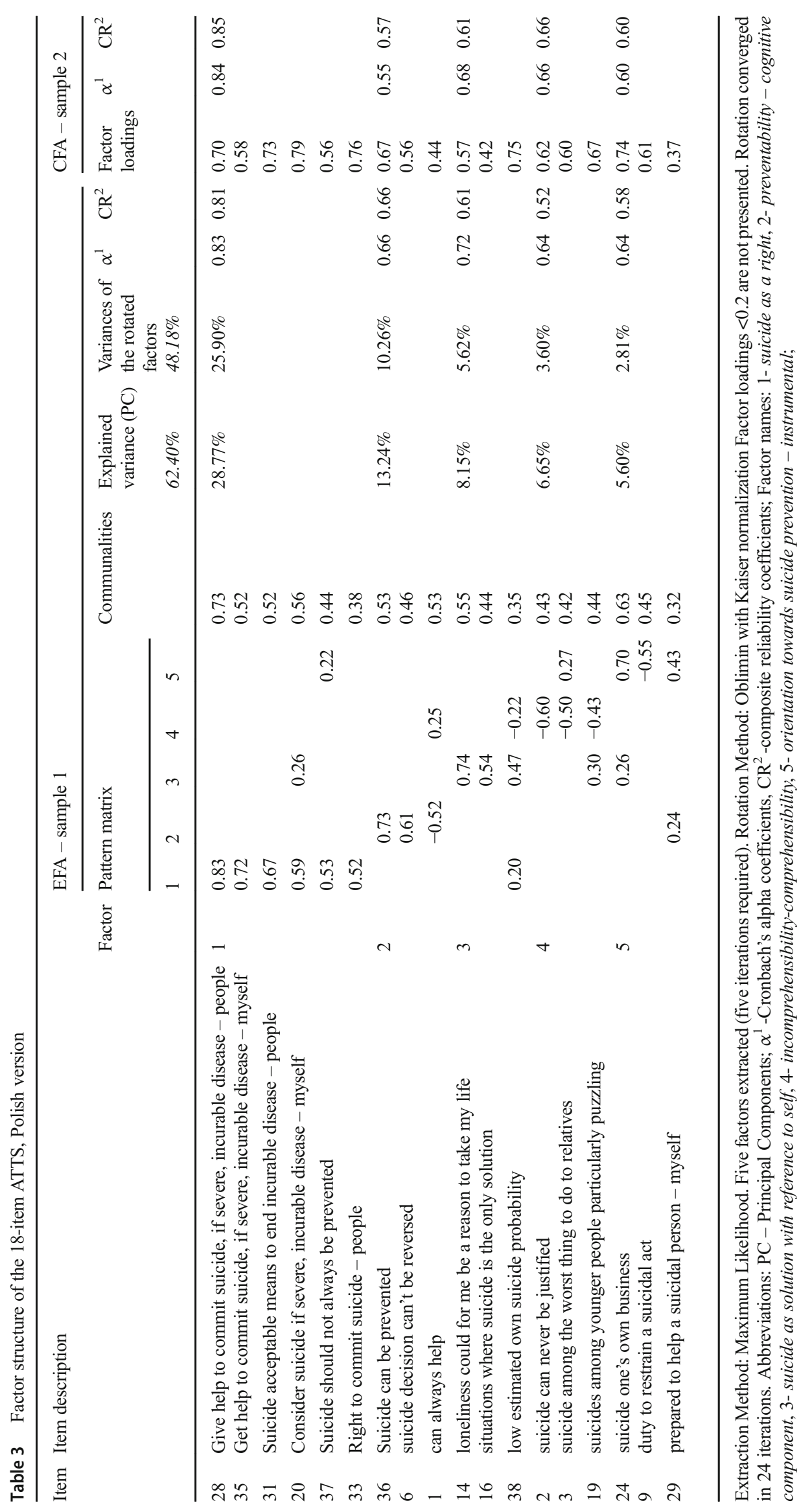


Table 4 CFA comparisons for the original and the proposed factor structure of the ATTS Scale

\begin{tabular}{|c|c|c|c|c|c|c|c|c|c|}
\hline Model & $\mathrm{CMIN/DF}$ & CFI & RMSEA & PCLOSE & AIC & GFI & RMR & AGFI & TLI \\
\hline Original 10 -factor ${ }^{\mathrm{a}}$ & 1.857 & 0.79 & 0.060 & 0.004 & 1121.05 & 0.82 & 0.09 & 0.78 & 0.75 \\
\hline Proposed 5-factor ${ }^{\mathrm{b}}$ & 1.617 & 0.89 & 0.070 & 0.040 & 295.266 & 0.86 & 0.10 & 0.81 & 0.86 \\
\hline
\end{tabular}

${ }^{a}$ Result for the original model: $\chi^{2}(482)=895.046, p<0.001,34$-item solution, analyses on sample one, no modification indices

${ }^{\mathrm{b}}$ Result for the proposed model: $\chi^{2}(122)=197.266, \mathrm{p}<0.001$, cross-validated 18-item solution

\section{Discussion}

The purpose of the current study was to develop and crossvalidate the factorial structure of the ATTS with a Polish sample of students of the helping professions. CFA found the fivefactor structure of the revised, 18-item ATTS to be a valid one. These results are consistent with the theoretical foundations used for developing the original ATTS (Sallander Renberg and Jacobsson 2003).

Mixed results were found regarding hypothesis 1 . The factorability and theoretical consistency of the 10-factor version were critically discussed and the results used as a rationale for proposing a different questionnaire design. Although a five-factor model was cross validated with the second sample, certain model fit coefficients and the internal consistency were below the expectations. Three factors of the questionnaire (1 - suicide as a right, 3 - suicide as a solution with reference to self, 4 - incomprehensibility - comprehensibility) comprise a comprehensive theoretical conceptualization of the positive/negative attitude towards suicide, based on the tripartile model (Allport 1935), referent level (self, people) (Diekstra and Kerkhof 1989) and type of attitude object (suicide act, a person with suicidal behavior and suicide prevention).

The tested model incorporated the concept of attitude towards suicide prevention, which was represented by two factors from the revised ATTS ( 2 - preventability - cognitive component, 5 - preventability - instrumental component). The readiness and willingness to prevent suicide might be regarded as behavioral presentations of positive attitudes towards a suicidal person. Suicide attitudes and helping behavior among physicians, psychologists or nursing professionals are related issues (Stevens and Nies 2018).

Hypothesis 2 was partially confirmed. Contrary to expectations, acceptance of suicide (expressed by comprehensibility, suicide as right to die and suicide as solution) was found to have only weak relationships with suicidal behavior and individualistic personal values. This result suggests that the association between suicide attitudes and behavior is a complex one, and similar to that observed between attitudes towards suicide and personal values. Although no relevant recommendation exists for estimating the criterion validity of suicide acceptance, it was determined in the present study by the relationship between suicide comprehensibility and self-reported suicidal behavior. This finding is consistent with previous studies (Gibb et al. 2006; Sallander Renberg and Jacobsson 2003); however, further investigations are required to confirm the criterion validity of the Polish ATTS scale. A different scale measuring a similar construct should be used to assess the concurrent validity of the revised ATTS.

The proposed five-factor model of the ATTS is unique because of including only theoretically sound items. For that

Table 5 Comparison between male and female responses on the ATTS factors and latent factor correlations

\begin{tabular}{|c|c|c|c|c|c|c|c|c|}
\hline & \multicolumn{2}{|l|}{ Factor } & \multirow[t]{2}{*}{ Mean score } & \multirow[t]{2}{*}{ SD } & \multicolumn{4}{|c|}{$\begin{array}{l}\text { CFA } \\
\text { Latent factor correlations }\end{array}$} \\
\hline & & Sex & & & 2 & 3 & 4 & 5 \\
\hline $1^{3}$ & Suicide as a right ${ }^{1}$ & $\begin{array}{l}\mathrm{F} \\
\mathrm{M}\end{array}$ & $\begin{array}{l}16.70 \\
17.18\end{array}$ & $\begin{array}{l}5.32 \\
5.53\end{array}$ & -0.20 & 0.79 & -0.68 & -0.42 \\
\hline $2^{3}$ & Preventability -cognitive component ${ }^{2}$ & $\begin{array}{l}\mathrm{F} \\
\mathrm{M}\end{array}$ & $\begin{array}{l}11.81 \\
11.61\end{array}$ & $\begin{array}{l}2.19 \\
2.18\end{array}$ & & -0.47 & 0.20 & 0.48 \\
\hline $3^{3}$ & Suicide as a solution with reference to self ${ }^{2}$ & $\begin{array}{l}\mathrm{F} \\
\mathrm{M}\end{array}$ & $\begin{array}{l}6.27 \\
6.45\end{array}$ & $\begin{array}{l}2.59 \\
2.88\end{array}$ & & & -0.82 & -0.38 \\
\hline $4^{3}$ & Incomprehensibility-Comprehensibility $^{2}$ & $\begin{array}{l}\mathrm{F} \\
\mathrm{M}\end{array}$ & $\begin{array}{l}9.86 \\
9.34\end{array}$ & $\begin{array}{l}2.98 \\
2.92\end{array}$ & & & & 0.17 \\
\hline $5^{3}$ & Preventability -instrumental compoment ${ }^{2}$ & $\begin{array}{l}\mathrm{F} \\
\mathrm{M}\end{array}$ & $\begin{array}{l}11.60 \\
12.00\end{array}$ & $\begin{array}{l}2.37 \\
2.16\end{array}$ & & & & \\
\hline
\end{tabular}

Theoretical range of score: ${ }^{1} 6-30,{ }^{2} 3-15 ;{ }^{3}$ No significant differences of mean values between females and males; data from sample 2 
Table 6 Criterion validity of the Polish ATTS scale - Pearson correlations

\begin{tabular}{llllll}
\hline Criterion & Measurement & ATTS subscale & Sex & r & p \\
\hline Suicidal behavior & GHQ-D Subscale D & suicide as a right & F & 0.28 & $<0.001$ \\
& & & M & 0.22 & 0.060 \\
& & Total & 0.26 & $<0.001$ \\
& incomprehensibility & F & 0.34 & $<0.001$ \\
& -comprehensibility & M & 0.28 & 0.015 \\
& & Total & 0.32 & $<0.001$ \\
\hline
\end{tabular}

GHQ-28 General Health Questionnaire; data from sample 1 reason, the examined model incorporating 18 items is not consistent with previous studies (Hjelmeland et al. 2008; Ji et al. 2016; Sallander Renberg 2001; Sallander Renberg and Jacobsson 2003; Williams and Witte 2018). This could have been also affected by differences between values and suicide perception across cultures. A five-factor model was also determined by Williams and Witte (Williams et al. 2018); however, the authors suggest that the factors did not represent interpretable content. Some similarities in factor structure exist for factors described as "preventability/inevitability", and "acceptability/comprehensitiliby" in previous studies (Ji et al. 2016; Sallander Renberg and Jacobsson 2003; Williams and Witte 2018).

These differences can be explained partly by the existence of cultural diversity between the studied populations and the application of the ATTS in a specific sample. Some of the underlying constructs of the ATTS (Sallander Renberg and Jacobsson 2003) could be irrelevant to certain groups within Polish society, which represents an obstacle for the Polish validation. It has been found that variations in ATTS questionnaire factor structure are needed to compensate for differences in culture and study group (Ji et al. 2016; Sallander Renberg and Jacobsson 2003; Siau et al. 2017).

This issue was partially addressed in the present study by providing a detailed content interpretation of the factors. For practical purposes, the factor names in the present validation refer to those proposed by Sallander Renberg and Jacobsson (2003).

Factor 1 (suicide as a right) is consistent with the original scale and is loaded by six items. High scores can be interpreted as attitude beliefs towards suicide with reference to self and others, such as recognition of suicide in the case of severe or incurable disease, and respect for the end-of-life decision of another person.

Factor 2 (preventability - cognitive component) is consistent with the original ATTS factor structure and is loaded by three items. It concerns the attitude towards suicide prevention in its cognitive aspect. High scores can be interpreted as a strong belief that it is possible to help someone with suicidal thoughts, certainty about the reversibility of suicidal behavior and positive associations with prevention. Factor 2 refers to the cognitive component of an attitude towards suicide prevention.
Factor 3 (suicide as solution with reference to self), loaded by three items, is unique and has not been identified in previous studies employing the ATTS. High scores in this category indicate that an individual perceives suicide as an ultimate but reasonable solution, and agrees with the fact that he or she might be capable of considering suicide in the future or under certain circumstances. This concerns the instrumental component of approaching vs avoidance towards attitude object, which is suicidal behavior.

Factor 4 (incomprehensibility-comprehensibility) is similar in content to the incomprehensibility factor in the original 10factor structure; however, it consists of only three items. The factor comprises ambivalent and rather aversive associations of emotional valence with suicidal behavior. High scores indicate confusion about the reasons to die by suicide, blaming people committing suicides for traumatizing those in bereavement or condemning suicide. Factor 4 emphasizes the negative aspects of the attitude, while factor 1 represents more positive associations.

To some extent, factor 5 (preventability - instrumental component) is consistent with the original factor "preparedness to prevent". The dimension comprises three items, with high scores reflecting an individual's orientation towards suicide prevention, readiness to involve with intervention, and sense of duty to restrain a suicidal act. Low scores may also indicate withdrawal, low self-efficacy in establishing contact with a suicidal person and tabooing suicidal behavior. In contrast to factor 2 , which refers to the cognitive aspect of preventability, factor 5 concerns the instrumental component with reference to the self or others.

Regarding cultural diversity, the perception of suicidal behavior among the general population in Poland is a separate issue. A study investigating functioning after suicidal attempts by Tsirigotis et al. (2011) found that persons with their own suicidal history in Poland displayed increased self-destructiveness, manifested by helplessness towards everyday events and passiveness. Being overwhelmed and self-destructive may be attributed to the stigmatization and self-stigmatization of those who commit suicide in Poland. Stigmatization is highly associated with negative social perception of people with mental problems (Babicki et al. 2018) and religious beliefs penalizing suicide (Stack 2013). In addition, Polish society tends to be 
more collectivist than those of most European countries, places strong family responsibilities on the individual (Sorokowski et al. 2017). In this case, suicidal behavior might have negative impact to everyone involved as it would be a violation of social norms and environmental expectations. It is possible that the results of the Polish adaptation of the ATTS may have been affected by cultural specificity, and that the understanding of suicide acceptance as a right and suicide comprehensibility in the Polish sample may differ from other countries.

Sallander Renberg and Jacobsson (2003) attribute the relatively low internal consistency of the original ATTS questionnaire to its complexity and the broad area of the attitudes it covers. To address this, the revised model of suicide-related attitudes proposed in the present study is less complex and more consistent. Nevertheless, as attitudes towards suicide are multifaceted, and hence often conflicting and unstable, it is unlikely that this type of measurement tool would achieve high total internal consistency (Sallander Renberg and Jacobsson 2003).

Since the Polish ATTS scale is the first instrument on suicide attitudes to be adopted in Poland, it was impossible to compare the scores with those of a matching questionnaire of determined validity. Therefore, the following steps were taken to ensure construct validity: elimination of unrelated items, elimination of items of questionable relationship to the concept of attitude, elimination of items with low communalities, use of the maximum likelihood method for EFA instead of principal component analysis and elimination of two-item factors. Finally, an additional CFA was performed on the second sample to confirm the ATTS factor structure.

One key limitation of the present study is the relatively small size of the samples, which might affect the problem of result generalization, the correctness of the factor structure and the average error in eigenvalues (Costello and Osborne 2005). In addition, the results could be influenced by the selection criteria employed in the Polish validation, including the convenience sampling method.

A further problem may be presented by the model fit of the Polish ATTS scale and the theoretical relevance of the identified factors. Although the proposed model demonstrated a better fit for the 18-item ATTS than the original version, not all model fit parameters are acceptable. Secondly, although the tool was intended to assess the cognitive, emotional and behavioral components of attitudes towards suicide, the items concerning emotional judgment tend to be underrepresented. Most of the factor 4 (incomprehensibility - comprehensibility) items focus on negative judgment, being used to measure unipolar emotions, and some of the items seem not to distinguish emotions from cognitions: a notable limitation to the questionnaire. However, there is abundant room for further development of the attitude indicators; for example, certain emotional dimensions of attitudes towards suicide such as fear, anger or admiration could be also considered.

Taken together, the findings provide a modified psychometric tool measuring explicit attitudes towards suicide and suicide prevention. The original version of ATTS is not recommended in Poland, due its low data fit, flawed design and theoretical inconsistency. In contrast, the revised Polish ATTS scale provides more comprehensible data interpretation, demonstrates more consistency with the general definition of attitude and the tripartile model and has better psychometric properties than the original version. It may be of value for studying the role played by different components of attitudes towards suicide and suicide prevention and their the relationship with behavior. However, the ATTS should still be interpreted with caution, and it is still too early for approval in a clinical setting. Nevertheless, the revised ATTS may serve as comparator scale for introducing a new comprehensive tool measuring attitudes towards suicide and suicide prevention.

The existence of relatively high suicide rates within the Polish community (World Health Organization 2017) calls attention to the attitudes towards suicide and suicide prevention borne by both the gatekeepers and the general population; these have considerable significance in vulnerability to suicide, help-seeking behavior and healthcare providers' reactions towards people at suicide risk (Horowitz et al. 2012; Stevens and Nies 2018; Tait and Michail 2014). The revised ATTS can help in monitoring suicide attitudes; however, to improve attitudes towards suicide prevention, suicide management should involve providing gatekeepers with prevention techniques and enhancing their capacity to care (Stevens and Nies 2018).

Acknowledgments The authors would like to sincerely thank those people who helped in this project, including Prof. Wiesław Szymczak, Prof. Ellinor Sallander Renberg, Dr. Katarzyna Nowakowska-Domagała, Ms. Klaudia Sowiak and MA Edward Lowczowski.

Funding This study was funded by the University of Lodz Grant (grant no. B1711800001608.02).

\section{Compliance with Ethical Standards}

Ethical Approval All procedures performed in studies involving human participants were in accordance with the ethical standards of the institutional and/or national research committee and with the 1964 Helsinki declaration and its later amendments or comparable ethical standards.

Informed Consent Informed consent was obtained from all individual participants included in the study.

\section{Conflict of Interest None.}

Open Access This article is distributed under the terms of the Creative Commons Attribution 4.0 International License (http:// 
creativecommons.org/licenses/by/4.0/), which permits unrestricted use, distribution, and reproduction in any medium, provided you give appropriate credit to the original author(s) and the source, provide a link to the Creative Commons license, and indicate if changes were made.

Publisher's Note Springer Nature remains neutral with regard to jurisdictional claims in published maps and institutional affiliations.

\section{References}

Ahmedani, B. K. (2011). Mental health stigma: Society, individuals, and the profession. Journal of social work values and ethics, 8(2), 41416. https://doi.org/10.1016/j.biotechadv.2011.08.021.Secreted.

Allport, G. W. (1935). Attitudes. In Handbook of Social Psychology (1st ed., pp. 798-844). https://doi.org/10.4135/9781412956253.

Anderson, A. L., Lester, D., \& Rogers, J. R. (2008). A psychometric investigation of the suicide opinion questionnaire. Death Studies, 32(10), 924-936. https://doi.org/10.1080/07481180802440258.

Arnautovska, U., \& Grad, O. T. (2010). Attitudes toward suicide in the adolescent population. Crisis, 31(1), 22-29. https://doi.org/10.1027/ 0227-5910/a000009.

Arrindell, W., \& Van Der Ende, J. (1985). An empirical test of the utility of the observations-to-variables ratio in factor and components analysis. Applied Psychological Measurement, 9(2), 165-178. https:// doi.org/10.1177/014662168500900205.

Babicki, M., Kotow Icz, K., Piotrowski, P., Stramecki, F., Kobyłk, A., \& Rymaszewska, J. (2018). Areas of stigma and discrimination of mentally ill people among internet respondents in Poland. Psychiatria Polska, 52(1), 93-102. https://doi.org/10.12740/PP/ 76861.

Bałandynowicz, A. (2016). Suicide in social awareness. Suicydologia, 8 , 87-95.

Batterham, P. J., Calear, A. L., \& Christensen, H. (2013). The stigma of suicide scale: Psychometric properties and correlates of the stigma of suicide. Crisis, 34(1), 13-21. https://doi.org/10.1027/0227-5910/ a000156.

Brunero, S., Smith, J., Bates, E., \& Fairbrother, G. (2008). Health professionals' attitudes towards suicide prevention initiatives. Journal of Psychiatric and Mental Health Nursing, 15(7), 588-594. https://doi. org/10.1111/j.1365-2850.2008.01278.x.

Cerny, B., \& Kaiser, H. (1977). A study of a measure of sampling adequacy for factor- analytic correlation matrices. Multivariate Behavioral Research, 12(1), 43-47. https://doi.org/10.1207/ s15327906mbr1201.

Costello, A. B., \& Osborne, J. W. (2005). Best practices in exploratory factor analysis : Four recommendations for getting the most from your analysis. Practical Assessment, Research \& Education, 10, 19. Available online: http://pareonline.net/getvn.asp?v=10\&n=7. Accessed 20 Feb 2019

Csikai, E. L. (1999). The role of values and experience in determining social workers' attitudes toward euthanasia and assisted suicide. Social Work in Health Care, 30(1), 75-95 21p. https://doi.org/10. 1300/J010v30n01 05.

Diekstra, R. F., \& Kerkhof, A. J. F. (1989). Attitudes towards suicide. The development of a suicide-attitude questionnaire (SUIATT). In R. F. W. Diekstra, S. R. Maris, S. Platt, A. Schmidtke, \& G. Sonnek (Eds.), Suicide and its prevention: The role of attitude and imitation (pp. 91-107). Leiden: Canberrs, Brill.

Domino, G. (1980). Altering attitudes toward suicide in an abnormal psychology course. Teaching of Psychology, 7(4), 239-240. https://doi.org/10.1207/s15328023top0704_15.

Domino, G., Moore, D., Westlake, L., \& Gibson, L. (1982). Attitudes toward suicide: A factor analytic approach. Journal of Clinical
Psychology, 38(2), 257-262. https://doi.org/10.1002/10974679(198204)38:2<257::AID-JCLP2270380205>3.0.CO;2-I.

Eskin, M. (2013). The effects of individualistic-collectivistic value orientations on non-fatal suicidal behavior and attitudes in Turkish adolescents and young adults. Scandinavian Journal of Psychology, 54, 493-501. https://doi.org/10.1111/sjop.12072.

Fabrigar, L., MacCallum, R., Wegener, D., \& Strahan, E. (1999). Evaluating the use of exploratory factor analysis in psychological research. Psychological Methods, 4(3), 272-299. https://doi.org/10. 1037/1082-989X.4.3.272.

Farberow, N. L. (1989). Attitudes towards suicide. In R. F. W. Diekstra, S. R. Maris, S. Platt, A. Schmidtke, \& G. Sonnek (Eds.), Suicide and its prevention: The role of attitude and imitation (pp. 281-298). Leiden: Canberrs, Brill.

Gagnon, J., \& Hasking, P. A. (2012). Australian psychologists' attitudes towards suicide and self-harm. Australian Journal of Psychology, 64(2), 75-82. https://doi.org/10.1111/j.1742-9536.2011.00030.x.

Gearing, R. E., \& Lizardi, D. (2009). Religion and suicide. Journal of Religion and Health, 48(3), 332-341. https://doi.org/10.1007/ s10943-008-9181-2.

Ghasemi, P., Shaghaghi, A., \& Allahverdipour, H. (2015). Measurement scales of suicidal ideation and attitudes: A systematic review article. Health Promotion Perspectives, 5(3), 156-168. https://doi.org/10. 15171/hpp.2015.019.

Gibb, B. E., Andover, M. S., \& Beach, S. R. H. (2006). Suicidal ideation and attitudes toward suicide. Suicide and Life-threatening Behavior, 36(1), 12-18. https://doi.org/10.1521/suli.2006.36.1.12.

Gmitrowicz, A., Makara-Studzińska, M., \& Młodożeniec, A. (2015). Suicide Risk in Adolescents [Ryzyko samobójstwa u młodzieży]. Warsaw: Wydawnictwo Lekarskie PZWL.

Goldberg, D., Williams, P., Makowska, Z., \& Merecz, D. (2001). The assessment of mental health on the base of questionnaire research by David Goldberg. The handbook for users of GHQ-12 and GHQ-28 [in polish: Ocena zdrowia psychicznego na podstawie badań kwestionariuszami Davida Goldberga. Podręcznik dla użytkowników . Łódź: Instytut Medycyny Pracy im. Prof. J. Nofera.

Goldsmith, S.K., Pellmar, T.C., Kleinman, A.M., Bunney, W.E. (Eds.). (2002). Reducing Suicide: A National Imperative. Washington, DC, US: National Academic Press.

Grimholt, T. K., Haavet, O. R., Jacobsen, D., Sandvik, L., \& Ekeberg, O. (2014). Perceived competence and attitudes towards patients with suicidal behaviour: A survey of general practitioners, psychiatrists and internists. BMC Health Services Research, 14(1). https://doi. org/10.1186/1472-6963-14-208.

Grube, J. W., Mayton, D. M., \& Ball-Rokeach, S. J. (1994). Inducing change in values, attitudes, and behaviors: Belief system theory and the method of value self-confrontation. Journal of Social Issues, 50(4), 153-173. https://doi.org/10. 1111/j.1540-4560.1994.tb01202.x.

Herron, J., Ticehurst, H., Appleby, L., Perry, A., \& Cordingley, L. (2001). Attitudes toward suicide prevention in front-line health staff. Suicide \& Life-Threatening Behavior, 31(3), 342-347. https://doi.org/10. 1521/SULI.31.3.342.24252.

Hitlin, S., \& Pinkston, K. (2013). Values, attitudes, and ideologies: Explicit and implicit constructs shaping perception and action. In Handbook of Social Psychology (p. 571). https://doi.org/10.1007/ 978-94-007-6772-0.

Hjelmeland, H., Knizek, B. L., Espeland, B., \& Aarethun, V. (2006). Attitudes towards suicide and suicide prevention as a base for intervention. Psychiatria Danubina, 18(Suppl. 1), 106.

Hjelmeland, H., Akotia, C. S., Owens, V., Knizek, B. L., Nordvik, H., Schroeder, R., \& Kinyanda, E. (2008). Self-reported suicidal behavior and attitudes toward suicide and suicide prevention among psychology students in Ghana, Uganda, and Norway. Crisis, 29(1), 20 31. https://doi.org/10.1027/0227-5910.29.1.20. 
Horowitz, L. M., Bridge, J. A., Teach, S. J., Ballard, E., Klima, J., Rosenstein, D. L., Wharff, E. A., Ginnis, K., Cannon, E., Joshi, P., $\&$ Pao, M. (2012). Ask suicide - screening questions (ASQ): A brief instrument for the pediatric emergency department. Archives of Pediatrics \& Adolescent Medicine, 166(12), 1170-1176.

Ji, N. J., Hong, Y. P., \& Lee, W. Y. (2016). Comprehensive psychometric examination of the attitudes towards suicide (ATTS) in South Korea. International Journal of Mental Health Systems, 10(1), 2. https:// doi.org/10.1186/s13033-016-0035-0.

Jost, J. T., Napier, J. L., Thorisdottir, H., Gosling, S. D., Palfai, T. P., \& Ostafin, B. (2007). Are needs to manage uncertainty and threat associated with political conservatism or ideological extremity? Personality and Social Psychology Bulletin, 33(7), 989-1007. https://doi.org/10.1177/0146167207301028.

Kerkhof, A. J. F. M., \& Natawat, S. S. (1989). Suicidal behavior and attitudes towards suicide among students in India and the Netherlands. A cross-cultural comparison. In R. F. W. Diekstra, S. R. Maris, S. Platt, A. Schmidtke, \& G. Sonnek (Eds.), Suicide and its prevention: The role of attitude and imitation (pp. 144-159). Leiden: Canberrs, Brill.

Kodaka, M., Poštuvan, V., Inagaki, M., \& Yamada, M. (2011). A systematic review of scales that measure attitudes toward suicide. International Journal of Social Psychiatry., 57, 338-361. https:// doi.org/10.1177/0020764009357399.

MacCallum, R. C., Widaman, K. F., Zhang, S. B., \& Hong, S. H. (1999). Sample size in factor analysis. Psychological Methods, 4(1), 84-99. https://doi.org/10.1037/1082-989x.4.1.84.

McAuliffe, C., Corcoran, P., Keeley, H. S., \& Perry, I. J. (2003). Risk of suicide ideation associated with problem-solving ability and attitudes toward suicidal behavior in university students. Crisis, 24(4), 160-167. https://doi.org/10.1027//0227-5910.24.4.160.

Moskowitz, G. B. (2005). Social cognition: Understanding self and others. New York: Guilford Press.

Nia, H., Lehto, R., Ebadi, A., \& Peyrovi, H. (2016). Death anxiety among nurses and health care professionals: A review article. International Journal of Community Based Nursing and Midwifery, 4(1), 2-10.

Peterson, R. A., \& Kim, Y. (2013). On the relationship between coefficient alpha and composite reliability. Journal of Applied Psychology, 98(1), 194-198. https://doi.org/10.1037/a0030767.

Reynders, A., Kerkhof, A., Molenberghs, G., \& Van Audenhove, C. (2014). Attitudes and stigma in relation to help-seeking intentions for psychological problems in low and high suicide rate regions. Social Psychiatry and Psychiatric Epidemiology, 49(2), 231-239. https://doi.org/10.1007/s00127-013-0745-4.

Reynders, A., Kerkhof, A., Molenberghs, G., \& Van Audenhove, C. (2016). Stigma, attitudes, and help-seeking intentions for psychological problems in relation to regional suicide rates. Suicide and Life-threatening Behavior, 46(1), 67-78. https://doi.org/10.1111/ sltb. 12179 .

Ringel, E. (1983). Suicide prevention: Retrospective and outlook: On the occasion of the ten-year anniversary of the German Society for Suicide Prevention. Crisis: The Journal of Crisis Intervention and Suicide Prevention, 4(1), 3-15.

Robinson, J., Cox, G., Malone, A., Williamson, M., Baldwin, G., Fletcher, K., \& O'Brien, M. (2013). A systematic review of school-based interventions aimed at preventing, treating, and responding to suicide-related behavior in young people. Crisis: The Journal of Crisis Intervention and Suicide Prevention., 34, 164-182. https://doi.org/10.1027/0227-5910/a000168.

Rokeach, M. (1973). The nature of human values. New York Free Press, 70, 965-966. https://doi.org/10.2307/1959882.

Sallander Renberg, E. (2001). Self-reported life-weariness, death-wishes, suicidal ideation, suicidal plans and suicide attempts in general population surveys in the north of Sweden 1986 and 1996. Social Psychiatry and Psychiatric Epidemiology, 36(9), 429-436. https:// doi.org/10.1007/s001270170020.
Sallander Renberg, E., \& Jacobsson, L. (2003). Development of a questionnaire on attitudes towards suicide (ATTS) and its application in a Swedish population. Suicide \& Life-Threatening Behavior, 33(1), 52-64. https://doi.org/10.1521/suli.33.1.52.22784.

Schmidt, R. C. (2016). Mental health practitioners' perceived levels of preparedness, levels of confidence and methods used in the assessment of youth suicide risk. The Professional Counselor, 6(1), 76-88. https://doi.org/10.15241/rs.6.1.76.

Siau, C. S., Wee, L. H., Ibrahim, N., Visvalingam, U., \& Wahab, S. (2017). Cross-cultural adaptation and validation of the attitudes toward suicide questionnaire among healthcare personnel in Malaysia. Inquiry (United States), 54. https://doi.org/10.1177/ 0046958017707295.

Sisask, M., Varnik, A., Kolves, K., Bertolote, J. M., Bolhari, J., Botega, N. J., et al. (2010). Is religiosity a protective factor against attempted suicide: A cross-cultural case-control study. Archives of suicide research : official journal of the International Academy for Suicide Research, 14(1), 44-55. https://doi.org/10.1080/ 13811110903479052.

Sorokowski, P., Randall, A. K., Groyecka, A., Frackowiak, T., Cantarero, K., Hilpert, P., Ahmadi, K., Alghraibeh, A. M., Aryeetey, R., Bertoni, A., Bettache, K., Błazejewska, M., Bodenmann, G., Bortolini, T. S., Bosc, C., Butovskaya, M., Castro, F. N., Cetinkaya, H., Cunha, D., David, D., David, O. A., Dileym, F. A., Domínguez Espinosa, A. C., Donato, S., Dronova, D., Dural, S., Fisher, M., Hamamcioğlu Akkaya, A., Hamamura, T., Hansen, K., Hattori, W. T., Hromatko, I., Gülbetekin, E., Iafrate, R., James, B., Jiang, F., Kimamo, C. O., Koç, F., Krasnodębska, A., Laar, A., Lopes, F. A., Martinez, R., Meskó, N., Molodovskaya, N., Moradi Qezeli, K., Motahari, Z., Natividade, J. C., Ntayi, J., Ojedokun, O., Omar-Fauzee, M. S. B., Onyishi, I. E., Özener, B., Paluszak, A., Portugal, A., Realo, A., Relvas, A. P., Rizwan, M., Sabiniewicz, A. L., Salkicević, S., Sarmány-Schuller, I., Stamkou, E., Stoyanova, S., Šukolová, D., Sutresna, N., Tadinac, M., Teras, A., Ponciano, E. L. T., Tripathi, R., Tripathi, N., Tripathi, M., Yamamoto, M. E., Yoo, G., \& Sorokowska, A. (2017). Marital satisfaction, sex, age, marriage duration, religion, number of children, economic status, education, and collectivistic values: Data from 33 countries. Frontiers in Psychology, 8. https://doi.org/10.3389/fpsyg. 2017.01728 .

Stack, S. (2013). Religion and suicide acceptability: A review and extension. Suidicologi, 18(1).

Stevens, K. P., \& Nies, M. A. (2018). Factors related to nurses' attitudes towards the suicidal patient: An integrative review. Clinical Research and Trials, 4(2), 1-6. https://doi.org/10.15761/CRT. 1000211.

Suominen, K., Suokas, J., \& Lönnqvist, J. (2007). Attitudes of general hospital emergency room personnel towards attempted suicide patients. Nordic Journal of Psychiatry, 61(5), 387-392. https://doi.org/ 10.1080/08039480701643381.

Tabachnick, B., \& Fidell, L. (2013). Using multivariate statistics. Pearson Education (Vol. 6th ed.). https://doi.org/10.1037/022267.

Tait, L., \& Michail, M. (2014). Educational interventions for general practitioners to identify and manage depression as a suicide risk factor in young people: A systematic review and meta-analysis protocol. Systematic Reviews, 3(1). https://doi.org/10.1186/2046-40533-145.

Tsirigotis, K., Gruszczyński, W., Lewik-Tsirigotis, M., \& Kruszyna, M. (2011). Manifestations of indirect self-destructiveness in persons after suicide attempts. Psychiatria i Psychologia Kliniczna, 11(2).

van der Feltz-Cornelis, C.M., Sarchiapone, M., Postuvan, V., Volker, D., Roskar, S., Grum, A.T., Carli, V., McDaid, D., O'Connor, R., Maxwell, M., Ibelshäuser, A., Van Audenhove, C., Scheerder, G., Sisask, M., Gusmão, R., Hegerl, U. (2011). Best practice elements of multilevel suicide prevention strategies: A review of systematic reviews. Crisis: The Journal of Crisis Intervention and Suicide 
Prevention. 32(6), 319-333. https://doi.org/10.1027/0227-5910/ a000109

Wasserman, D. (2016). Suicide: An unnecessary death (2nd ed.). New York: Oxford University Press.

Williams, C., \& Witte, T. (2018). Media reporting on suicide: Evaluating the effects of including preventative resources and psychoeducational information on suicide risk, attitudes, knowledge, and help-seeking behaviors. Suicide and Life-threatening Behavior, 48(3), 253-270. https://doi.org/10.1111/sltb.12355.

Williams, C., Cero, I., Gauthier, J. M., \& Witte, T. (2018). Examination of the latent factor structure and construct validity of the stigma of suicide scale-short form. Death Studies, 42(10), 616-626. https:// doi.org/10.1080/07481187.2017.1416431.

Winterrowd, E., Canetto, S. S., \& Benoit, K. (2017). Permissive beliefs and attitudes about older adult suicide: A suicide enabling script? Aging and Mental Health, 21(2), 173-181. https://doi.org/10.1080/ 13607863.2015.1099609.
World Health Organization. (2010). Towards evidence-based suicide prevention Programmes. Geneva: WHO Western Pacific Region.

World Health Organization. (2017). Global Health Observatory data repository. Suicide rates, age-standardized. Data by country. http:// apps.who.int/gho/data/node.main.MHSUICIDEASDR?lang=en. Accessed 12 April 2017.

Zadravec, T., Grad, O., \& Sočan, G. (2006). Expert and lay explanations of suicidal behaviour: Comparison of the general population's, suicide attempters', general practitioners' and psychiatrists' views. International Journal of Social Psychiatry, 52(6), 535-551. https:// doi.org/10.1177/00207640060668408.

Zalsman, G., Hawton, K., Wasserman, D., van Heeringen, K., Arensman, E., Sarchiapone, M., Carli, V., Höschl, C., Barzilay, R., Balazs, J., Purebl, G., Kahn, J. P., Sáiz, P. A., Lipsicas, C. B., Bobes, J., Cozman, D., Hegerl, U., \& Zohar, J. (2016). Suicide prevention strategies revisited: 10-year systematic review. The Lancet Psychiatry, 3(7), 646-659. https://doi.org/10.1016/S2215-0366(16) 30030-X. 